\title{
Investigation on Prevalence of Sparganum mansoni Infection in Wild Frogs on Hainan Island of China
}

\author{
Ruijia Fu \\ Hainan Medical University \\ Pei Liang \\ Hainan Medical University \\ Gang LU \\ Hainan Medical University \\ Jinbao Gu \\ Southern Medical University \\ Dayong Wang ( $\nabla$ wangdy@hainanu.edu.cn ) \\ Hainan University
}

\section{Research}

Keywords: Sparganum mansoni, Sparganosis, Wild frogs, Infection, Hainan Island

Posted Date: December 1st, 2020

DOI: https://doi.org/10.21203/rs.3.rs-114639/v1

License: (c) (i) This work is licensed under a Creative Commons Attribution 4.0 International License.

Read Full License 


\section{Abstract}

Background: Sparganosis is a serious food-borne parasitic zoonosis, which is mainly caused by ingesting or open-wound contact of the frog flesh infected by Sparganum mansoni, or even by intake of the water contaminated by the parasite. The purpose of the study was to explore the prevalence of sparganum infection in wild frogs distributed throughout the Hainan Island, which is the largest island of the mainland of China and located at the northwest of the South China Sea, and to analyze the risk in local populations to suffer from sparganosis.

Methods: From 2018 to 2020, wild frogs were collected from rural ponds, rivers and farmlands in different cities and counties throughout the Hainan Island. After weighing and marking of the frogs, the sparganums were examined and isolated. The sites of the parasite and the number of infections of each frog were recorded and analyzed by statistics analysis.

Results: A total of 1556 of wild frogs were examined and isolated. 201 wild frogs were found to be infected by sparganum, and the natural infection rate of sparganum in wild frogs was $12.92 \%$ (201/1556). There were 612 sparganums found in the frogs, and the average was 3.04 per frog, while the highest infection rate of wild frogs was in Baoting, up to $32.93 \%(27 / 82)$. The infection rate of sparganum in wild frogs in the central region of Hainan Island is higher than other regions. Most sparganums were located in the hind legs of frog, and the number of the sparganum infection in the frogs was not related to the species and weight of the frogs.

Conclusions: On Hainan Island, sparganum infection in wild frogs is relatively common, and constitutes a potential threat to human. Effective measures should be taken to control the incidence of sparganosis.

\section{Background}

Sparganum mansoni is the larvae of Spirometra mansoni, which is also the main stage of infection and causes disease to the human body. Sparganums can invade the brain, eyes, abdominal cavity, spinal cord, and subcutaneous tissues of humans causing a serious parasitic zoonosis known as sparganosis. The source of sparganums causing the infection comes from many vertebrates, but it is mainly parasitic in the body of frogs and snakes. Frog is the second important intermediate host of Spirometra mansoni, and is a very important source of sparganum infection in human. Human infection is resulted mainly from ingesting raw or incompletely cooked flesh of frogs infected by sparganums, or placing frog flesh as poultice on open wound for treatment of skin ulcers or eye inflammations [1-3].

Sparganosis has a global distribution [4-7], but most cases occur in East and Southeast Asian countries [8-10]. So far, over 1,000 cases of sparganosis have been reported in 25 provinces, province-level municipalities and autonomous regions in china [11-12]. In Hainan Island which is the mainland of the Hainan province, human cases of sparganosis have also been reported [11]. In southern China, eating raw frog meat is a traditional diet for many local people. Sparganum infection in frogs have been reported in a number of provinces in China, such as Jiangxi, Anhui, Guangxi, Henan, Guizhou, Zhejiang, Shanxi and 
Guangdong [13-24]. The natural infection rate of sparganum in frogs varies from region to region, which is related to factors such as the living environment, living habits, and the number of hosts investigated.

The warm and humid weather in Hainan Island is very suitable for the survival of frogs, and the local people have used frogs as food since ancient times, which has created the prerequisites for the spread of sparganosis. Therefore, collecting frogs and separating the Sparganosis mansoni in their bodies is of great significance for the epidemiological investigation related to sparganosis. The aims of this study were to explore the prevalence of Sparganum mansoni infection in wild frogs in Hainan Island, and analyze the risk of local population to suffer from sparganosis.

\section{Methods}

\section{Survey sites}

The present study was carried out in Hainan Island located at the northwest of South China Sea. This area was geographically separated from Leizhou Peninsula of the continent of Asia by Qiongzhou Strait, between the eastern longitudes of $108^{\circ} 37^{\prime}-117^{\circ} 50^{\prime}$ and northern latitudes of $3^{\circ} 58^{\prime}-20^{\circ} 20^{\prime}$. It belongs to the tropical monsoon climate. As one of the provinces and the largest island of the mainland of China, Hainan province consists of 19 cities and counties with a total population about 9.45 million, eighteen of them are located on Hainan Island,. The land area of Hainan Island is about 3.39 square kilometers. According to different geographic locations with the distribution of water systems, the 18 cities and counties located on Hainan Island were selected as the survey sites. The 19th city located on coral reefs with a small population of about 500 people is not included in the survey.

All frogs were collected from different sites in the 18 cities and counties on Hainan Island from 2018 to 2020 , including local rural ponds, rivers and farmlands. The collected frogs are wild frogs, mostly Rana tigrina and Rana plancyi which are common species in the nature, with some frogs of other species.

\section{Inspection of Sparganum mansoni infection}

The frogs were weighed, numbered and registered, and then anesthetized and sacrificed in the laboratory. The Sparganum mansoni in the frog muscles were examined under a stereomicroscope with the naked eyes after stripping off the skin. Once identified, the sparganums were removed from the muscle and put in a culture dish containing physiological saline. After measurement and morphological observation, most of the white sparganums appear as flat ribbons of $1 \mathrm{~cm}$ to $8 \mathrm{~cm}$ in length, and the maximum length of some individuals reached $12 \mathrm{~cm}$. They are highly active and able to change shape in physiological saline. The parasitic site of each infected frog and the number of sparganum infection were examined to calculate the extent of the sparganum infection.

\section{Statistical analysis}


Original data were recorded and sorted using the Microsoft $\circledast$ Excel, and all statistical analyses were conducted using SPSS 13.0. The numbers of the frogs infected by sparganums collected from different cities and counties were compared by the chi-square test $(\chi 2)$. A $p$-value less than 0.01 was considered statistically significant.

\section{Results}

A total of 1556 individual wild frogs were examined collected from all 18 survey sites. It was found that 201 wild frogs were parasitized by Sparganum mansoni. The total natural infection rate was $12.92 \%$ (201/1556). There were 612 sparganums found in those frogs, and the average infection rate was 3.04 per frog. The maximum number of sparganums identified in a single frog was 22 . There was a statistically significant difference in the infection rate of sparganums in the wild frogs collected from different cities and counties $(\chi 2=97.633, P=0.000)$, whereas the highest incidence of infection in wild frogs was in Baoting County, up to $32.93 \%$ (27/82) (Table 1, Fig. 1).

According to different geographical locations, we divide the 18 cities and counties of Hainan Province into eastern coastal regions (Haikou, Wenchang, Qionghai, Wanning, Lingshui, Sanya), central regions (Ding'an, Tunchang, Qiongzhong, Wuzhishan, Baoting), Baisha) and the western coastal regions (Chengmai, Lin'gao, Danzhou, Changjiang, Dongfang, Ledong). Statistically significant difference in the infection rate of Sparganum mansoni in the wild frogs was found in these three geological regions $(\chi 2=$ $35.919, P=0.000$ ), whereas the highest infection rate was in the midland of Hainan Island, up to $19.53 \%$ (109/558) (Table 2, Fig. 2).

Among the 1556 sampled frogs, the infection rate of Sparganum mansoni in Rana plancyi was $14.56 \%$ (90/618). There were 268 sparganums found in those frogs, and the average infection intensity was 2.98 per frog. The incidence of sparganosis in Rana tigrina was 11.78\% (105/891), 323 sparganums were found, and the average infection intensity was 3.08 per frog. In addition, there were 47 frogs not classified, the infection rate in which was $12.77 \%$ (6/47). Twenty one sparganums were found in these frogs, and the average infection intensity was 3.5 per frog. There was no significant difference in the infection of sparganum between different frog species. $(\chi 2=2.505, P=0.286)$ (Table 3$)$.

The frogs were divided into 4 groups according to their body weights, namely $<30 \mathrm{~g}$ group, $30-60 \mathrm{~g}$ group, $60-90 \mathrm{~g}$ group, and $>90 \mathrm{~g}$ group. The infection rates of Sparganum mansoni in these groups were $14.11 \%(46 / 326), 14.12 \%(62 / 439), 11.42 \%$ (70/613) and 12.92\% (23/178) accordingly. There was no significant difference in the infection rate in each group $(X 2=2.203, P=0.531)$. The $60 \otimes 90$ g group and $>$ $90 \mathrm{~g}$ group had higher average intensity of infection, 3.77 per frog and 4.22 per frog respectively (Table 4 , Fig. 3).

Sparganum mansoni can be widely parasitic in various parts of the frog's body, and it is more common in muscle tissue. By analyzing the data of the 201 frogs infected by sparganums, we found that most sparganums were located in the hindleg muscle, up to 447 parasites with an average infection intensity of 3.08 per frog. The infection rate was also the highest in the hindleg muscles, reaching $72.14 \%$ 
(145/201), followed by $20.89 \%$ (42/201) on the back, forelegs $13.93 \%(28 / 201)$, abdomen $10.45 \%$ (21/201), and body cavity $3.48 \%$ (7/201) (Table 5, Fig. 4 \& Fig. 5).

\section{Discussion}

Hainan Island locates in the very south of China, a tropical region. The climate is warm throughout the year, with plentiful rainfalls, proper humidity, and abundant crops in the farmland, which is very suitable for the growth and reproduction of a large number of frogs. It also provides optimal natural conditions for the reproduction and spread of sparganums.

The investigation showed that Sparganum mansoni were isolated in 1,556 wild frogs, and a total of 612 parasites were detected. Among them, up to 22 sparganums were detected in a single frog. The natural infection rate of Sparganum mansoni in wild frogs in Hainan Island is $12.92 \%$, and the average infection intensity was 3.04 per frog, indicating that the sparganums are widely distributed in various regions of the island, and the phenomenon of sparganamu infection in wild frogs is common (Table 1). Although the infection rate in the wild frogs in Hainan Island is lower than many other areas in China, as indicated by the survey in Henan Island by Deng et al. (26.6\%) [17], the survey in Guangzhou by Hong et al. (51.9\%) [22], and the survey in Yulin by Xie et al. (77.6\%) [15], there are still many people who are not aware of sparganum infection in wild frogs, and perform insufficient protection of sparganosis. Especially in recent years, with the changes of eating habits, more and more people start to eat frog meat. Some local people in Hainan Island have the habit of preying on wild frogs. Although there is no confident evidence showing that locals eat raw frog meat, insufficient heating or incomplete cooking process may still cause sparganum infection.

In this research, we found that wild frogs in different areas are infected by Sparganum mansoni in different situations(Fig. 1)related to factors such as ecological environment, geographical location, climate, local customs and habits. A total of 341 sparganums were colletected from the central region, which had high rate of sparganum infection in wild frogs compared with other regions ( $19.53 \%$ ) (Table 2). The infection rate in Baoting and Ding'an counties located in the central region are higher (32.93\%) and (27.48\%) than other places, suggesting that people of these two regions have a higher risk of sparganosis than in other regions. The central area of Hainan Island is the birthplace of main rivers on the island, with an average annual rainfall of more than 2,200 $\mathrm{mm}$, rich freshwater resources and good water quality. There are many ponds, reservoirs and rice fields suitable for the living and reproduction of frogs. In Baoting county and Wuzhishan city, the original ecological environment is relatively well preserved, and there are more free-range cats and dogs in the area. Free-range cats and dogs have more chances to take wild frogs as foods, and be infected by sparganums. The eggs in their feces can easily enter the water after being washed by rain, thereby forming a natural circulation and reiterative transmission, which provides a better chance for completion of the life cycle of Spirometra mansoni [20]. The infection rate of sparganum in wild frogs in Qionghai city and Dongfang city is zero, and the infection rate in Changjiang county and Lin'gao county is not high (Fig. 1). This may be related to the fact that the collection point is close to the sea. The sea is relatively far from highly crowded living areas of 
people, so there are less cats and dogs, which are also important sources of infection of sparganum, and actions should be taken to prevent the feces of cats and dogs to enter the water bodies closely related to human's daily life [25]. It has been reported in literatures that no sparganum infection was found in manually farmed frogs, which may be related to the lack of intermediate hosts required for a complete life cycle of Spirometra mansoni in the farms during manual breeding process, such as cats, dogs, and Cyclopes [26-27]. Frogs manually bred is fed with artificial foods, the frogs have less chance to contact with the outside world and have less chance of preying on cyclopes. In addition, manual breeding environments are generally sterilized and disinfested, which reduces the infection rate of sparganum [28].

The frogs collected in the study are mainly Rana tigrina and Rana plancyi. The Rana tigrina is distributed in various regions and inhabits near water plants that are not far from the land. The body length of Rana tigrina is $60-120 \mathrm{~mm}$, and the largest can weigh up to $200 \mathrm{~g}$. The Gold-stripped frogs are mainly distributed in Baoting county and Wuzhishan city, they inhabits on aquatic plants in the ditch and is smaller in size. The results of the study showed that no significant difference in the infection rate of sparganum between different frog species (Table 3), however the tendency of difference in the infection rate was found among frogs of different weights, though it is not statistically significant (Table 4). It was shown that the infection of sparganum is random, and they parasitize in frogs of different species and weights. Therefore, the infection rate is not related to them, but to the growth environments of the frogs. However, the infection intensity of sparganum in large frogs is relatively high (Fig. 3), indicating that the flesh of the hypertrophied frogs, which is rich in protein, calcium and phosphorus, especially the muscles of the hindlegs, provides abundant nutrients and plentiful space for the growth and development of sparganums. In addition, large frogs have lived for a longer time, and prolonged exposure to the wild environment will increase the probability of recurrent infection, leading to large scale infection.

Sparganum mansoni can be widely parasitized in various locations of the frog's body, and it is more common in muscle tissue. There will be edema in the area infected by sparganums, and some may have congestion or bleeding. The current results showed that the frog's hindleg muscles have the most parasites of sparganums, with 447 (Fig. 5), and the infection rate is also the highest (72.14\%) compared to other tissues, and the average infection intensity was 3.08 per frog (Table 5). The observation that sparganum is mainly parasitized in the leg muscles of frogs is consistent with the findings made by other domestic scholars $[14,15,17,23,24]$. It further indicates that sparganums have strong contractility and movtility, and it mostly extends under the skin or curls to live in the cavities in leg muscles, since frogs' leg muscles are more nutritious and provide better condition for the survival of sparganums.

On Hainan Island, wild frogs are infected by Sparganum mansoni commonly, which is a potential threat to local people. In order to prevent the infection of Sparganum mansoni, it is necessary to raise public awareness of sparganum infection in frogs and the associated risk of sparganosis, advocate healthy diet concepts and habits, and abandon capture, sale and purchase of wild frogs, so as to prevent and decrease the incidence of sparganosis [29].

\section{Declarations}


Acknowledgements

This work was supported by the National Nature Science Foundation of China (grant no.81560332), and by a Program of Hainan Association for Science and Technology Plan to Youth R\&D Innovation (QCXM201918).

\section{Authors' contributions}

RF wrote the original draft. PL and GL preformed the analysis. JG and DW reviewed and edited the manuscript. All authors read and approved the final manuscript.

\section{Availability of data and materials}

All data generated or analyzed during this study are included in this published article and its additional files.

\section{Consent for publication}

Not applicable.

\section{Competing interests}

The authors declare that they have no conflict of interest with the contents of this article.

\section{References}

1. Hong DJ, Xie HQ, Zhu M, Wan H, Xu RS, Wu YC. Cerebral sparganosis in mainland Chinese patients. J Clin Neurosci 2013;20(11):1514-1519.

2. Prasetyo RH, Safitri E. Sparganum in frog meat: A warning for the occurrence of human sparganosis. Trop Parasitol 2019;9(2):130-131.

3. Nithiuthaia S, Anantaphrutib MT, Waikagulb J, Gajadharc A. Waterborne zoo-notic helminthiases. Vet Parasitol 2004;126:167-193.

4. Berger L, Skerratt LF, Zhu XQ, Young S, Speare R. Severe sparganosis in Australian tree frogs. Journal of Wildlife Diseases 2009;45(4):921-929.

5. Bracaglia G, Ranno S, Mancinelli L, Santoro M, Cerroni L, Massone C, Sangueza O, Bravo FG, Diociaiuti A, Nicastri E, Muraca M, Boldrini R, Callea F, Putignani L. A waterborn zoonotic helminthiase in an Italian diver: a case report of a cutaneous Sparganum infection and a review of European cases. Pathog Glob Health 2015;109(8):383-386.

6. Griffin MP, Tompkins KJ, Ryan MT. Cutaneous sparganosis. Am J Dermatopathol 1996; 18 (1):70-72.

7. Czyzewska J, Namiot A, Koziolkiewicz K, Matowicka-Karna J, Dzieciol J, Kemona, H. The first case of human sparganosis in Poland and a review of the cases in Europe. Parasitol Int 2019;70: 89-91. 
8. Kim JG, Ahn CS, Sohn WM, Nawa Y, Kong Y. Human Sparganosis in Korea. J Korean Med Sci 2018;33(44):e273.

9. Yamashita K, Akimura T, Kawano K, et al. Cerebral sparganosis mansoni. Report of two cases. Surg Neurol 1990;33(1):28-34.

10. Anantaphruti MT, Nawa Y, Vanvanitchai Y. Human sparganosis in Thailand: an overview. Acta Trop 2011;118(3):171-176.

11. Li MW, Song HQ, Li C, Lin HY, Xie WT, Lin RQ, Zhu XQ. Sparganosis in mainland China. Int J Infect Dis 2011;3:e154-e156.

12. Lu G, Shi DZ, Lu YJ, Wu LX, Li LH, Rao LY, Yin FF. Retrospective epidemiological analysis of sparganosis in mainland China from 1959 to 2012. Epidemiol Infect 2014; 142(12): 2654- 2661.

13. Tong DS, Zhang Y, Hu NN, Hou R, Liang YS. Investigation on the infection of Sparganum mansoni in frogs at Farmers Market in Wuxi. Experimental and Laboratory Medicine 2017;35(6):965-966.

14. Zhu YX, Xu LF. Investigation on the infection of frogs with Spirometra mansoni in Huainan area. Chinese Journal of Zoonoses 2006;22(7):690.

15. Xie WH, Li JL, Wang XP, Zeng SY. Investigation on Spirometra mansoni sparganum infection of frogs in winter season in Yulin City. Journal Of Yulin Normal University 2003;24(3):70-72.

16. Zhou QA, Zeng Y, Shi YL, Li J,Zhang HM, Huang WY. Investigation on the Sparganum infection of commercial frogs and snakes in Nanning, Guangxi. Progress in Veterinary Medicine 2013;34(11):126-128.

17. Deng Y, Liu CJ, Chen WQ, Zhou RM, He LJ, Lin XM. Investigation on prevalence of Sparganum mansoni infection in frogs from Henan Province. Chinese Journal of Schistosomiasis Control 2012;24(1):82-84

18. Wu ZJ, Chen Y, Qiu XL, Jiang HT. Investigation of Sparganum Infection in frogs in Guiyang Farmers Market and 104 Clinical Cases. Journal of Guizhou Normal University 2007; 32 (2): 140-141+145.

19. Zhang HF, Wang GH, Lu B, Qian H, Guo MJ, Wu YX. Investigation on Sparganum mansoni infection and population knowledge, attitude and behavior in Tongxiang City, Zhejiang Province. Disease Surveillance 2018;33(2):172-174.

20. Yu YJ, Wang B, Gu MX, Xu ZQ, Ren CH, Wang ZG, Hu DB. Comparison of frogs infected with Sparganum mansoni in 2010 and 2015 in Ninghai County. Chinese Rural Health Service Administration 2016;36(9):1170-1171.

21. Li K, Li D, Fan WJ, Xu J, Han ZY, Sun J, Li P. Plerocercoid infection status of frogs and knowledge of residents to sparganosis in Taiyuan. Journal of Shanxi Medical University 2018;49(11):1316-1318.

22. Hong Q, Feng JP, Liu HJ, Li XM, Gong LR, Yang Z, Yang WM, Liang XF, Zheng RJ, Cui ZC, Wang WL, Chen DX. Prevalence of Spirometra mansoni in dogs, cats, and frogs and its medical relevance in Guangzhou, China. Int J Infect Dis 2016;53:41-45.

23. Lin YF, Yang PX, Xu GH, Chen WQ. Sparganum mansoni infection in frogs from Qingyuan city markets. Journal of Tropical Medicine 2014;14(12): 1649-1650+1656. 
24. Yang GD, Gong SP, Wang FM, Li WY, Wei YF, Ge Y, Xiao JJ. Investigation on the infection of edible frog Sparganum mansoni in some areas of Guangdong Province. Progress in Veterinary Medicine 2016;37(5):119-121.

25. Qiu MH, Qiu MD. Human Plerocercoidosis and Sparganosis: \. A Historical Review on Pathology, Clinics, Epidemiology and Control. Chin J Parasitol Parasit Dis 2009; 27 (3): 251-260.

26. Simpson C. Jabbar A, Mansfield CS, Tyrrell D, Croser E, Abraham LA. Gasser RB. Molecular diagnosis of sparganosis associated with pneumothorax in a dog. Mol Cell Probes 2012; 26(1): 60-62.

27. Woldemeskel M. Subcutaneous sparganosis, a zoonotic cestodiasis, in two cats. $J$ Vet Diagn Invest 2014;26 (2): 316-319.

28. Zhang XL, Mi RS, Zhang YH, Zhang SJ, Sun T, Jia HY, Huang Y, Gong HY, Han XG, Chen ZG. Low prevalence of spargana infection in farmed frogs in the Yangtze River Delta of China. Infect Genet Evol 2020;85:104466.

29. Yang GD. Xiao JJ. Wang FM. Deng YZ. Gong SP. The Review of Spirometra erinaceieuropaei Infection in Frogs and Countermeasures in China. Forestry and Environmental Science 2013;29(2):62-67.

\section{Tables}

Due to technical limitations, table PDF is only available as a download in the Supplemental Files section.

\section{Figures}




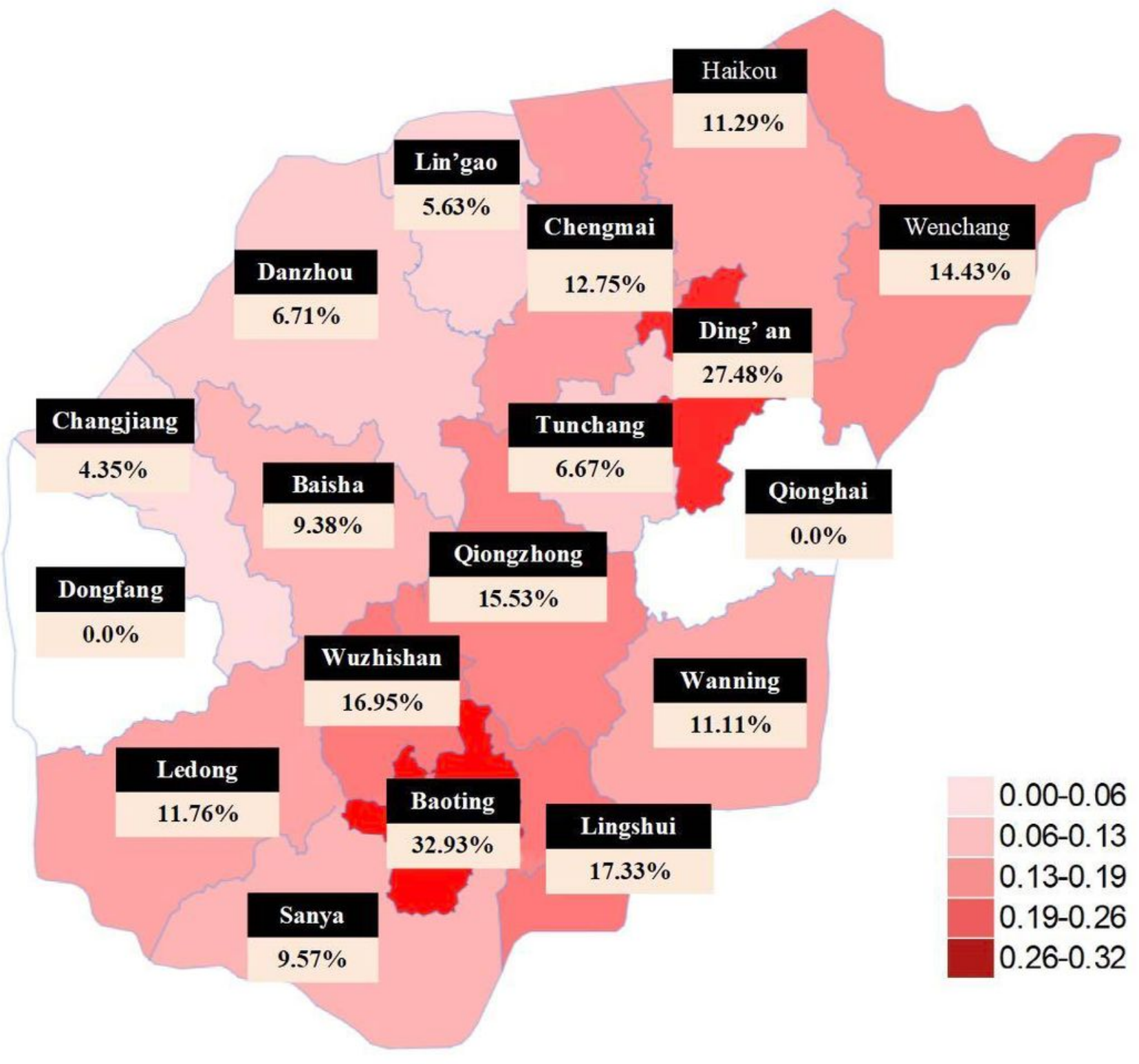

Figure 1

Distribution of sparganum infection in wild frogs on Hainan Island. Note: The designations employed and the presentation of the material on this map do not imply the expression of any opinion whatsoever on the part of Research Square concerning the legal status of any country, territory, city or area or of its authorities, or concerning the delimitation of its frontiers or boundaries. This map has been provided by the authors. 


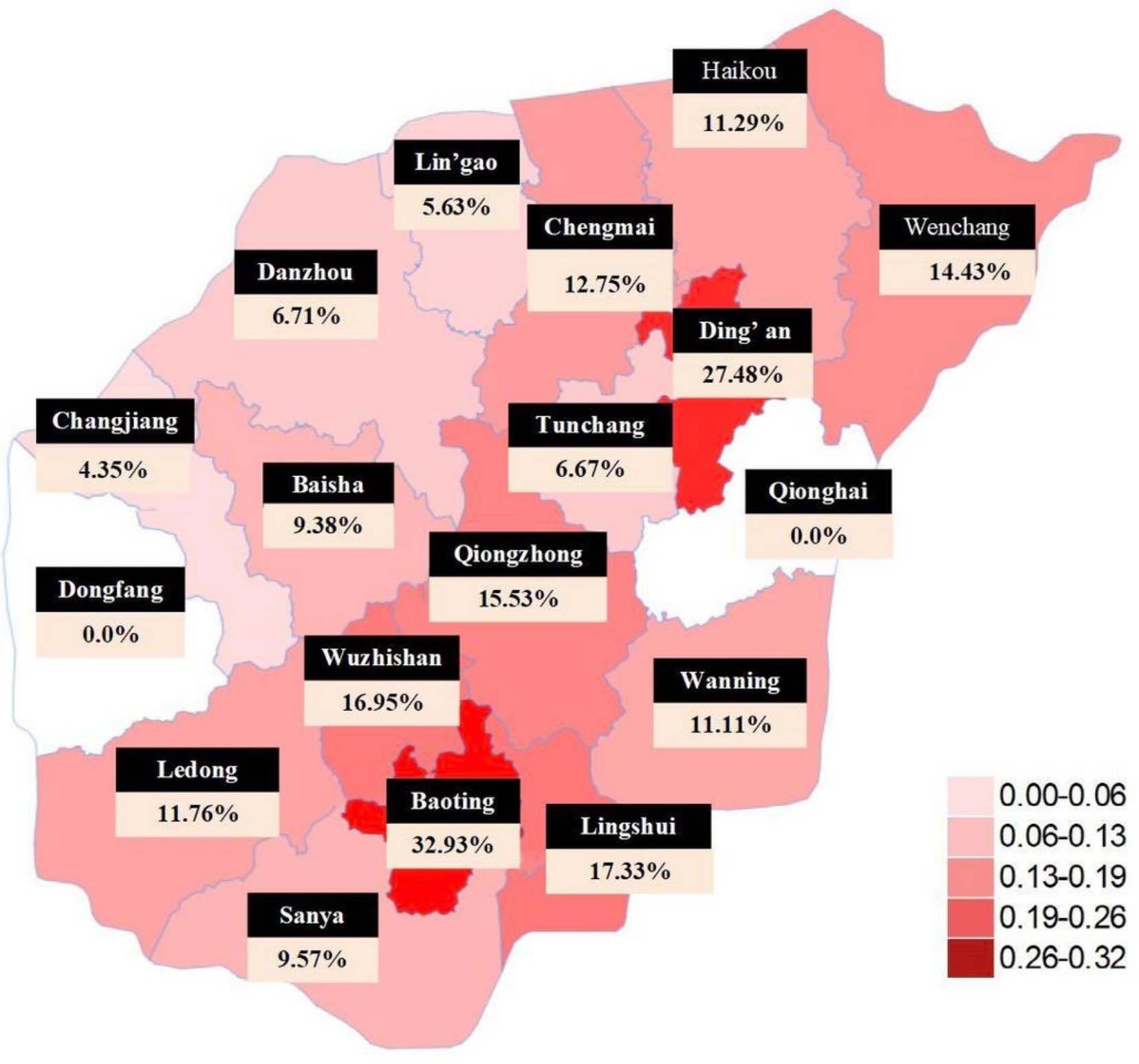

Figure 1

Distribution of sparganum infection in wild frogs on Hainan Island. Note: The designations employed and the presentation of the material on this map do not imply the expression of any opinion whatsoever on the part of Research Square concerning the legal status of any country, territory, city or area or of its authorities, or concerning the delimitation of its frontiers or boundaries. This map has been provided by the authors. 


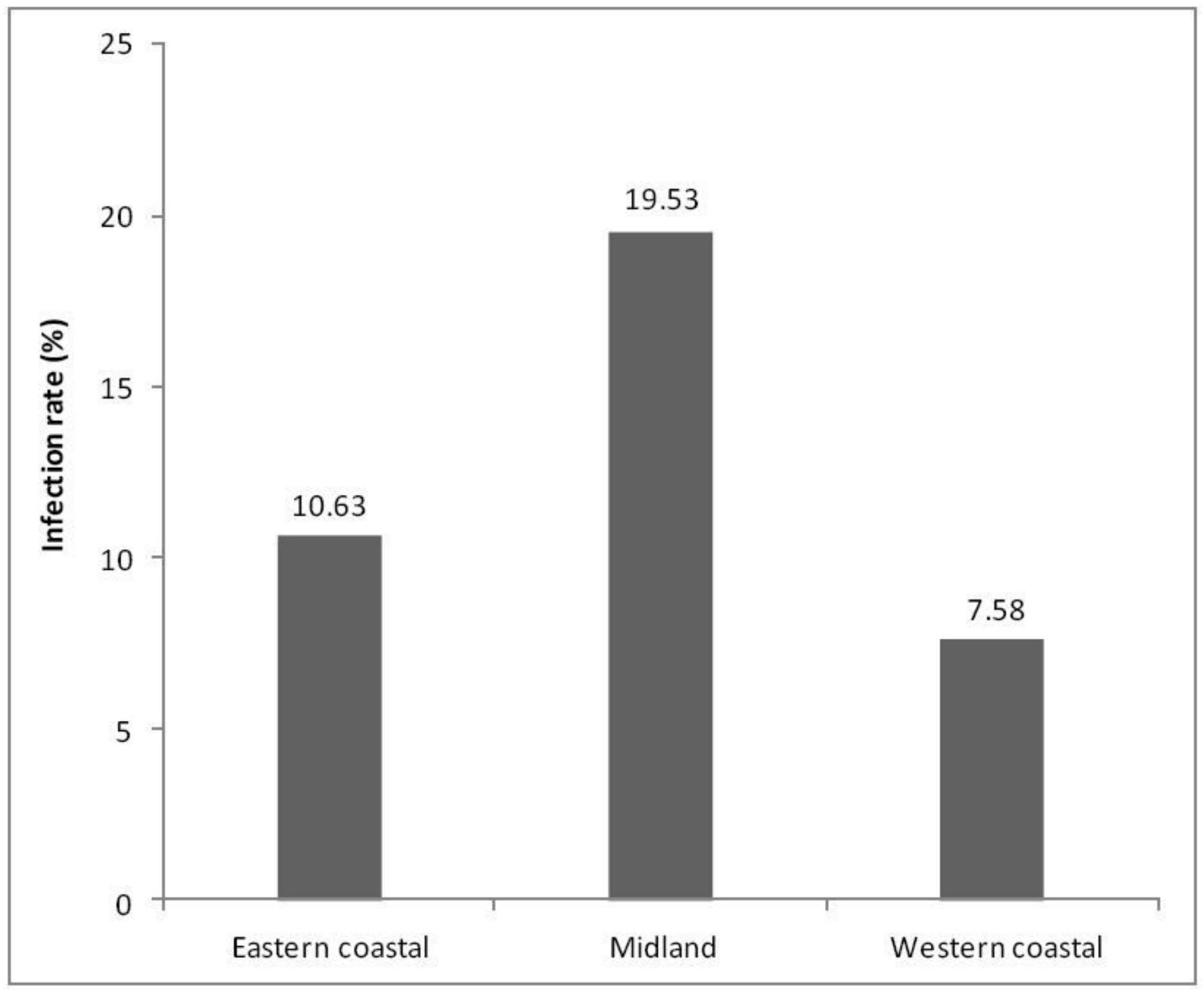

Figure 2

Summation of sparganum infection in the three geological areas on Hainan Island. 


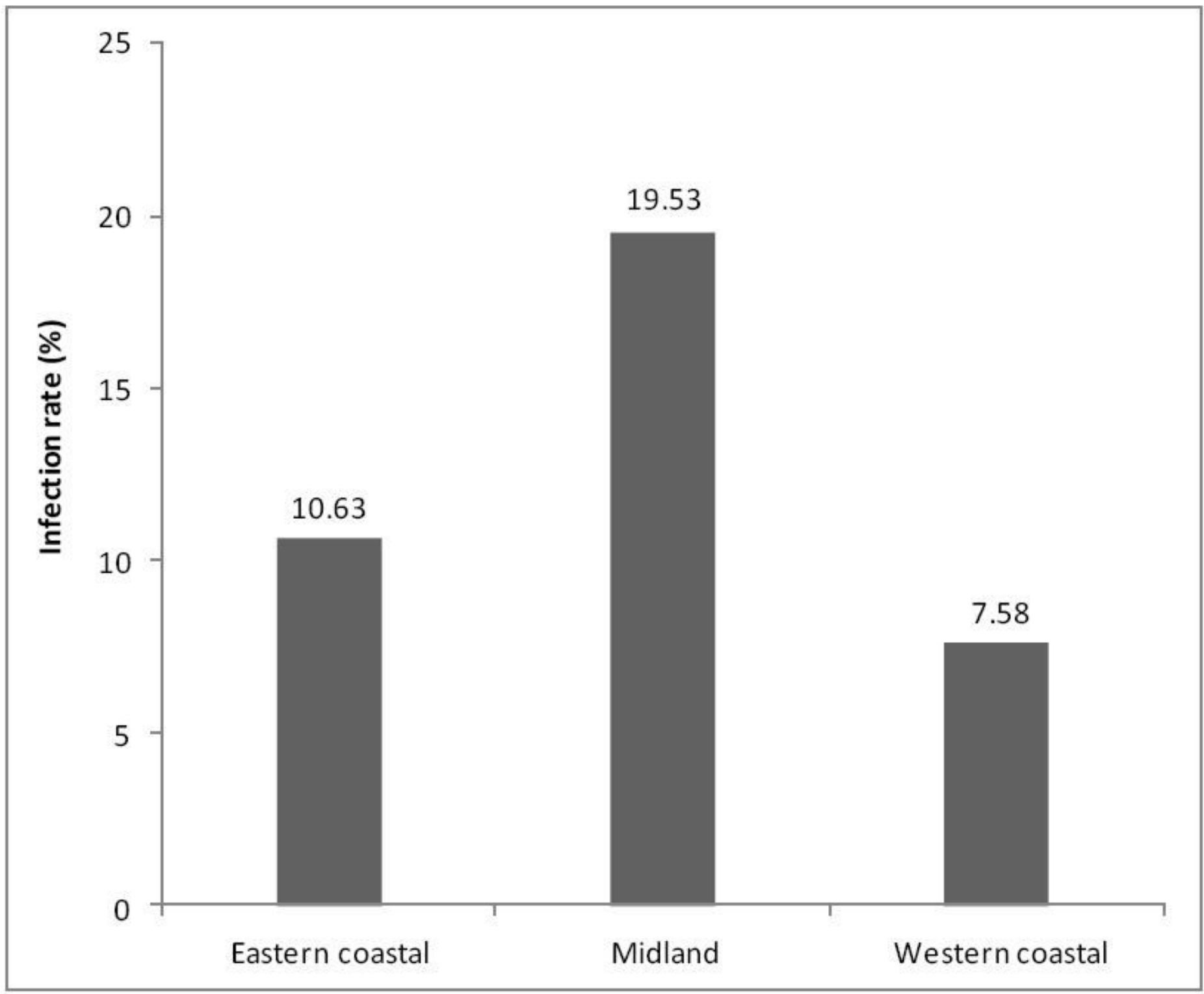

Figure 2

Summation of sparganum infection in the three geological areas on Hainan Island. 


\section{Infection intensity}

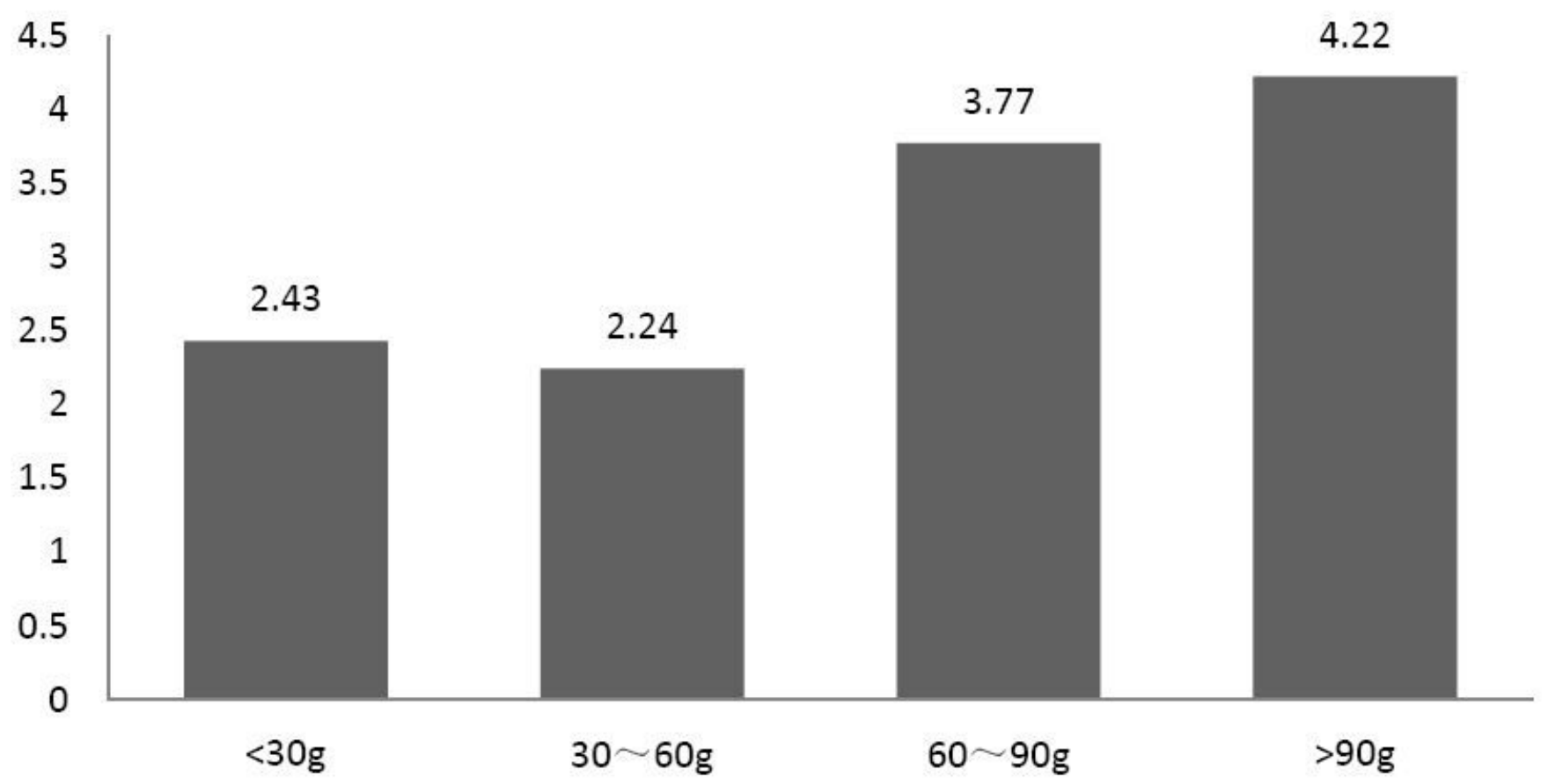

Figure 3

Illustration of the incidence of sparganum infection in frogs of different weight on Hainan Island. 


\section{Infection intensity}

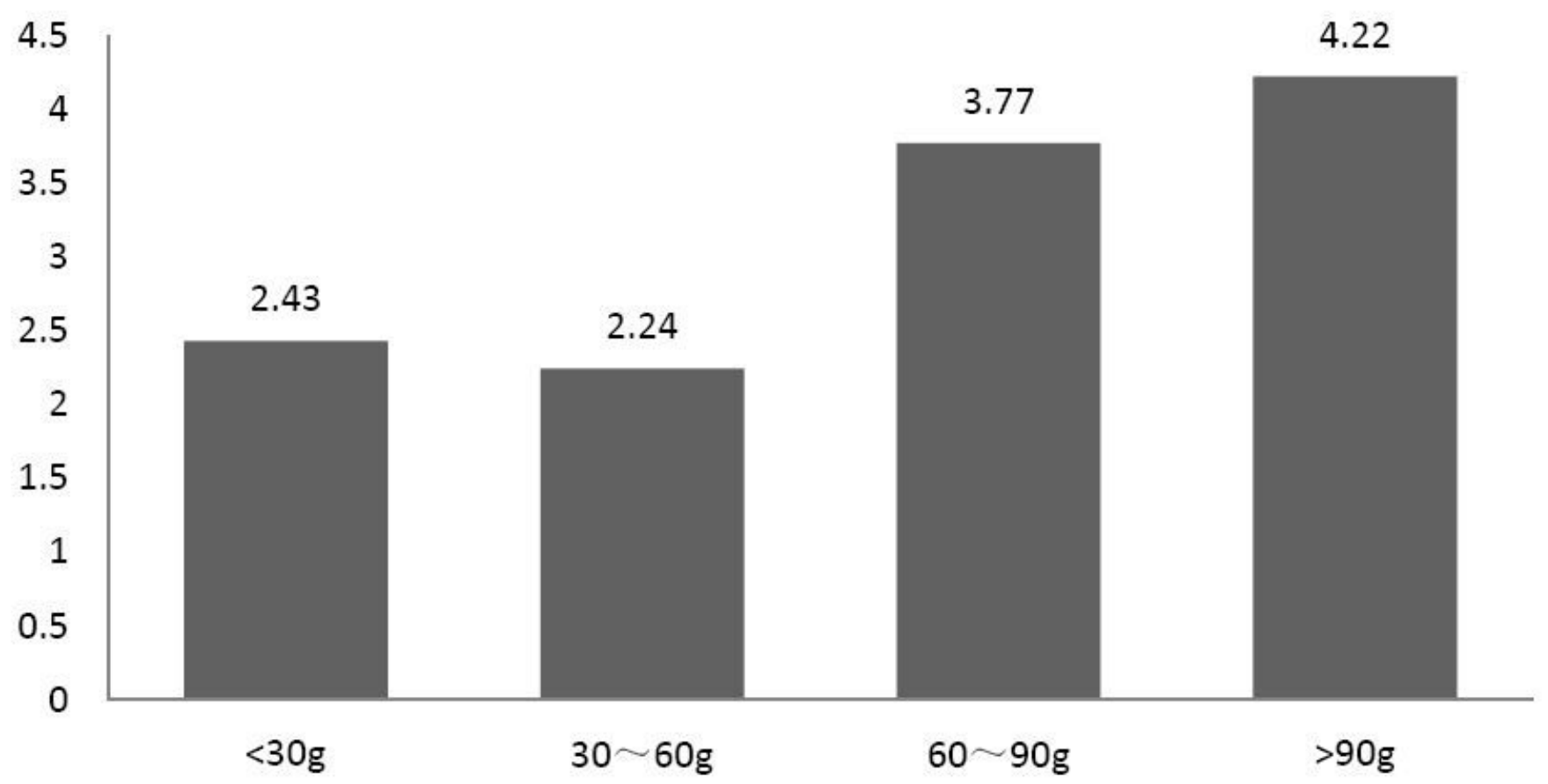

Figure 3

Illustration of the incidence of sparganum infection in frogs of different weight on Hainan Island. 


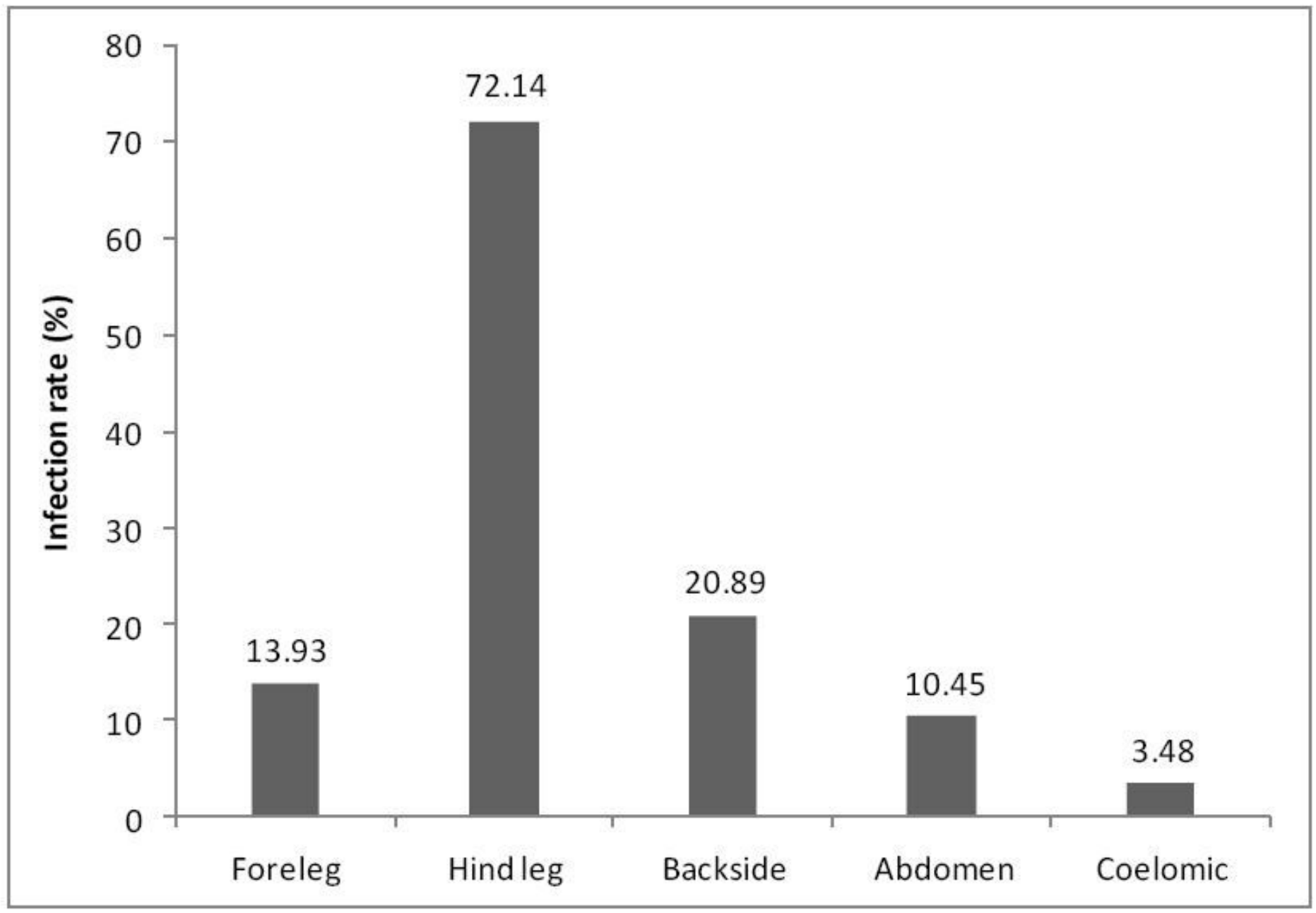

Figure 4

Illustration of the difference in parasitic location in the frogs collected from the 18 cities and counties on Hainan Island. 


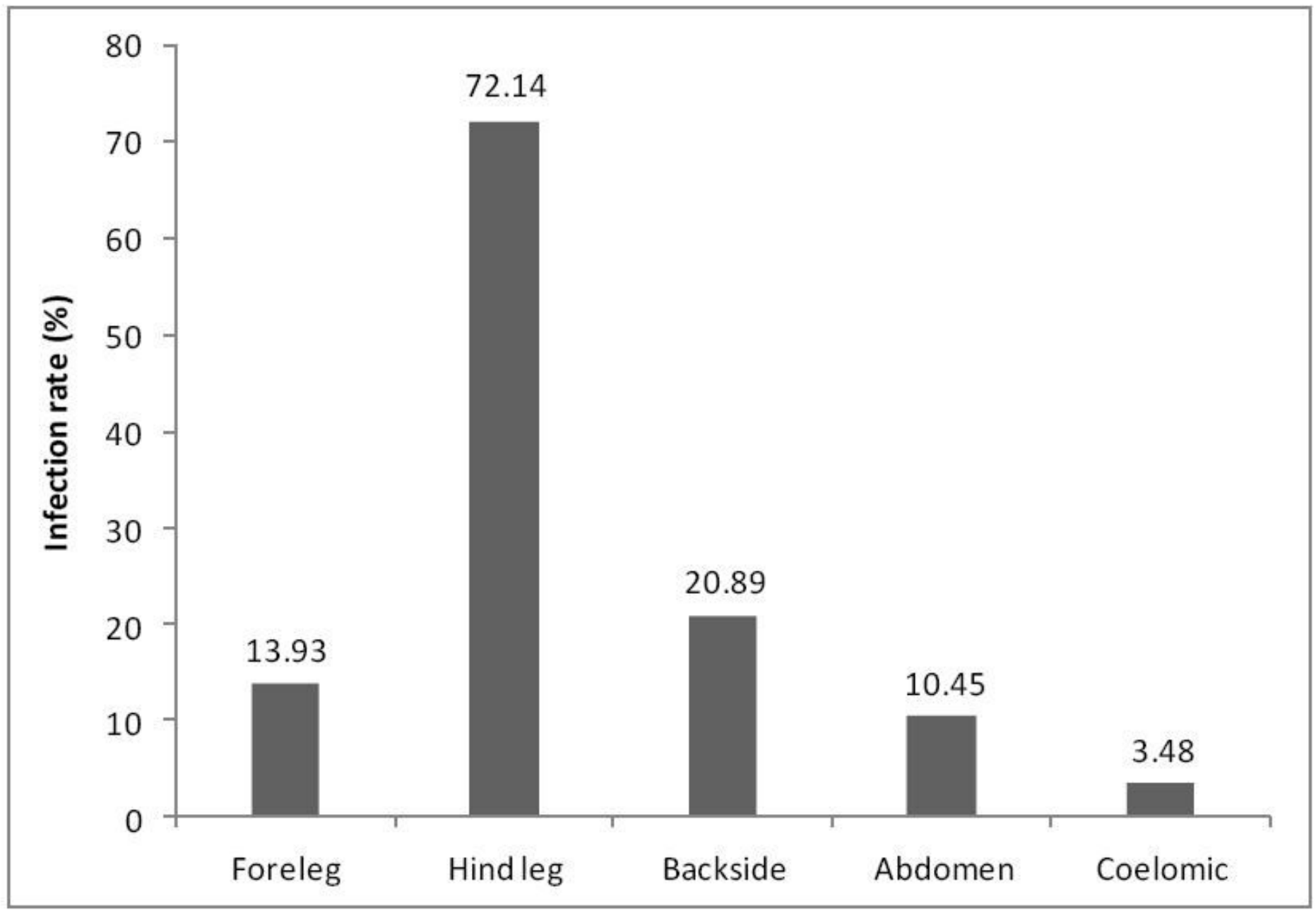

Figure 4

Illustration of the difference in parasitic location in the frogs collected from the 18 cities and counties on Hainan Island. 


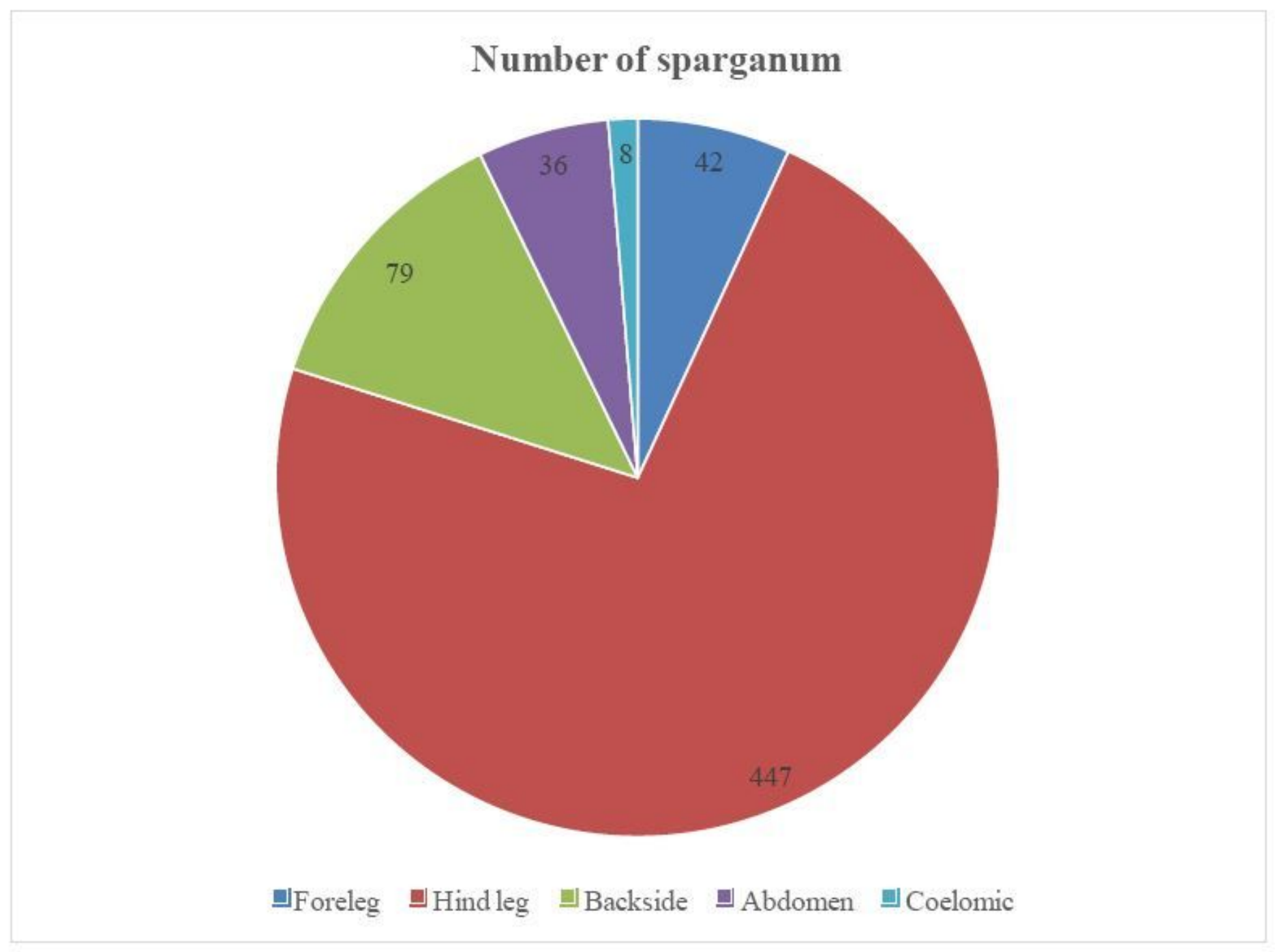

Figure 5

Distribution of sparganum in positive frogs. 


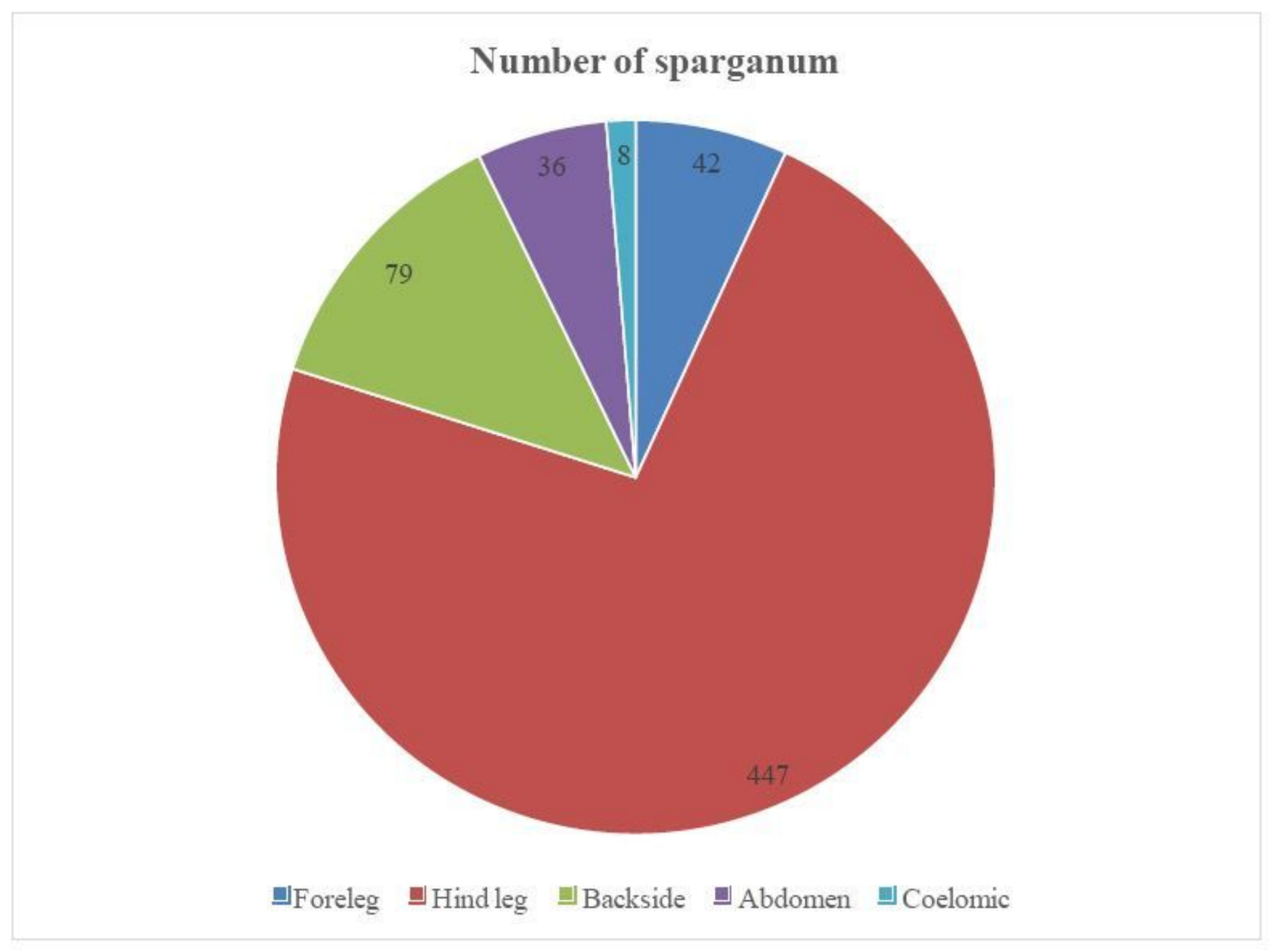

\section{Figure 5}

Distribution of sparganum in positive frogs.

\section{Supplementary Files}

This is a list of supplementary files associated with this preprint. Click to download.

- Tables.pdf

- Tables.pdf 